32. Извозчиков В.А. Методологические проблемы информатизации образования в контексте инфосферной эдукологии // Наука и школа. 1996. № 1. C. 23-26.

33. Коджаспирова Г.М., Коджаспиров А.Ю. Педагогический словарь: для студ. высш. и сред. пед. учеб. заведений. М.: Издательский центр «Академия», 2003. $176 \mathrm{c.}$

34. Ларионова М.А. Профессионально-педагогическое общение преподавателя современной высшей школы // Психопедагогика в правоохранительных органах. 2009. № 3 (38). С. 55-58.

35. Санникова С.В., Письменный Е.В. Ключевые компетенции в контексте Болонского процесса // Вестник Южно-Уральского государственного университета. 2009. Вып. 4. № 24. С. 57-62.
36. Аниськин В.Н., Бусыгина А.Л. Развитие коммуникативного интегративного компонента профессиональной компетентности преподавателя вуза в условиях холистичной информационно-образовательной среды // Балтийский гуманитарный журнал. 2017. T. 6, № 4 (21). C. 269-272.

37. Агумава Ф.Э. Цифровизация образования потребует изменений в законодательстве, считают сенаторы и эксперты [Электронный ресурс] // Парламентская газета. - https://pnp.ru/social/cifrovizaciyaobrazovaniya-potrebuet-izmeneniy-v-zakonodatelstveschitayut-senatory-i-eksperty.html.

38. Днепровская Н.В. Оценка готовности российского высшего образования к цифровой экономике // Статистика и экономика. 2018. Т. 15, № 4. С. 16-28.

\title{
CONCEPTUAL FOUNDATIONS OF HIGHER EDUCATION IN THE DIGITAL ECONOMY
}

(C) 2019

Bogoslovskiy Vladimir Igorevich, doctor of pedagogical sciences, professor of Information and Technological Education Department Herzen State Pedagogical University of Russia (Saint Petersburg, Russian Federation)

Busygina Alla Lvovna, doctor of pedagogical sciences, professor, head of Pedagogy and Psychology Department

Aniskin Vladimir Nikolayevich, candidate of pedagogical sciences, associate professor, dean of Mathematics, Physics and Computer Science Faculty, head of Physics, Mathematics and Teaching Methods Department Samara State University of Social Sciences and Education (Samara, Russian Federation)

Abstract. In the paper the authors identified seven key conceptual foundations of higher education based on the analysis of organizational and substantive features of networking, digitalization and on-lineization process of the Russian education system (NDORES), as a continuation of e-Learning development in the digital educational environment (DEE) and the results of the assessment of the Russian higher education readiness to the digital economy, obtained by N.V. Dneprovskoy. These include conceptual condition for the recognition of the leading role of the DEE in the system of «science - culture - learner - intelligence» for education subjects reflection development in human-machine systems and information society; optimization of continuous education concept on the basis of NDORES principles; directive change of educational process (EP) stereotypes in DEE; creation of a system of mandatory training and retraining of education subjects for daily learning and teaching activities in DEE; optimization, adaptation and digital transformation of the content of the main professional educational programs (MPEP) of training in the framework of existing and future Federal state educational standards of higher education (FSES HO); determination of effective motivational and value bases for communicative competence development of education the subjects in NDORES; changing legislative and policy approaches to the organization of NDORES, including provisions of the Labour code of the Russian Federation in the part concerning the rights and responsibilities of teachers carrying out their work in the context of DEE. The paper substantiates the demand for these conceptual foundations in the strategic and tactical directions of digitalization of higher education in the digital economy.

Keywords: digital economy; higher education; information of education; computer information technology (CIT); educational information and communication technology (EICT) of information-educational environment (IEE); eLearning; NDORES; DEE; digital information education (CIE); conceptual framework NDORES.

УДК 378.147

DOI 10.24411/2309-4370-2019-11302

Статья поступила в редакцию 27.12.2018

\section{ПРОБЛЕМЫ, СУЩНОСТЬ И ФОРМЫ ОРГАНИЗАЦИИ НАУЧНО-ИССЛЕДОВАТЕЛЬСКОЙ ДЕЯТЕЛЬНОСТИ СТУДЕНТОВ В СИСТЕМЕ ВЫСШЕГО ОБРАЗОВАНИЯ}

(C) 2019

\author{
Бражник Оксана Юрьевна, кандидат педагогических наук, \\ доцент кафедры педагогики и профессионального образования
}

Батраченко Екатерина Александровна, кандидат сельскохозяйственных наук, доцент кафедры географии Курский государственный университет (г. Курск, Российская Федерация)

Аннотация. В данной статье рассмотрены особенности организации научно-исследовательской деятельности студентов, обучающихся по направлению подготовки 05.04.02 География, направленность/ профиль Ландшафтное проектирование. Рассматриваются возможности реализации научно-исследовательской деятельности при реализации дисциплин вариативной части образовательной программы, а также модуля прак- 
тик. В данной статье акцентировано внимание на роли производственной практики в реализации научноисследовательской деятельности. Приводится примерное содержание программ практик, а также типология заданий для интенсификации научно-исследовательской работы. Особый акцент сделан на роли научноисследовательской деятельности в формировании общепрофессиональных и профессиональных компетенций. Рассматриваются особенности оценки и направления оптимизации научно-исследовательской работы при обучении в магистратуре. Проведенные исследования показали, что оценка сформированности компетенций может проводиться по различным показателям, основополагающее значение имеют следующие показатели: практический характер научно-инновационной деятельности (участие в фундаментальных ландшафтно-географических исследованиях, модернизации и созданию ландшафтных программ, имеющих общенаучное и прикладное значение), оригинальность идеи и креативный подход, использование новейших технологий ландшафтного планирования и проектирования.

Ключевые слова: высшее образование; научно-исследовательская работа; исследовательская компетентность; производственная практика; практика по получению профессиональных умений и навыков; общепрофессиональные компетенции; профессиональные компетенции; этап формирования компетенции.

Включение студентов в научно-исследовательскую деятельность, несомненно, открывает широкие возможности для формирования специалиста, адаптированного для решения научно-исследовательских и производственно-технологических задач в своей профессиональной области. Целью нашего исследования является определение роли производственной практики в реализации научно-исследовательской деятельности студентов, а также возможности организации различных форм включения студентов в научно-исследовательскую работу на разных этапах обучения. Научно-исследовательская деятельность студентов имеет достаточно длительную историю и в становлении прошла несколько этапов от научных студенческих кружков XIX века до настоящего времени (рис. 1).

К настоящему времени в теории и практике педагогики накоплен значительный опыт реализации данного вида деятельности. Анализ теоретических и практических изысканий в области проблем организации научно-исследовательской деятельности студентов позволяет сделать вывод, что данная проблема достаточно актуальна и не нова (А.С. Обухов, П.И. Пидкасистый, А.И. Савенков, Б.А. Ананьев, А. Маслоу, Ж. Пиаже, П.К. Энгельмейер, П.К. Анохин, М. Малкей, Т. Парсонс, Н. Стореридр, И.А. Зимняя, Т.И. Ерофеев, И.И. Ильясов, В.В. Краевский, А.М. Новиков, В.А. Сластенин, М.Г. Ярошевский, Т.К. Сметанина, А.В. Леонтович, Т.Ю. Цибизова, И.С. Алаторцева) [1-10].

Проблема приобщения студентов к научному творчеству и реализации их исследовательских способностей, несомненно, связано с качеством их профессиональной подготовленности [11]. Для диагностики особенностей содержания, организации и возможностей интенсификации научно-исследовательской деятельности обучающихся было реализовано анкетирование студентов естественно-географического факультета ФГБОУ ВО «Курский государственный университет» 1-4 курсов, обучающихся по направлению подготовки 05.03.02 - География, 05.03.06 - Экология и природопользование, а также студентов, обучающихся в магистратуре (направление подготовки 05.04.02 - География, 1-2 курс). Произведенный анализ позволил выявить следующие моменты: отмечены максимальные трудности организации и вовлечения студентов в научно-исследовательскую работу на образовательном уровне бакалавриата, преимущественно на 1-2 курсах. Некоторые студенты представляют этот вид деятельности в одностороннем порядке, в отрыве от реального образовательного процесса. Опрос показал, что только $30 \%$ студентов 1-го курса сопоставляют важность научно-исследовательской работы с успешным развитием себя в профессиональной деятельности. Заинтересованность и стремление к участию в научноисследовательской деятельности в структуре предпочтений по разным формам и видам деятельности уступает мероприятиям культурного досуга, общественной деятельности и другим видам. Тем не менее наблюдается высокая активность студентов в процессе освоения отдельных дисциплин, в методологическую и методическую базу которых заложены технологии проблемного обучения, интерактивные технологии, задачи, предполагающие элементы научных исследований. Например, при освоении дисциплины «Теория ландшафтной архитектуры и методология проектирования» студентам предлагается выполнить ряд задач исследовательского характера, например, выполнить проектирование новой ландшафтно-рекреационной зоны в условиях развития новых селитебных районов.

Несомненно, перспективным является участие студентов в различных научных проектах и конкурcax. В течение нескольких лет (2013-2018 гг.) студенты участвуют в мульдисциплинарном научном проекте, реализуемом совместно с Институтом археологии Российской академии наук «Реконструкция палеогеографической ситуации и специфики освоения территории Суджанского района (Курская область) носителями раннеславянских культур (IIIVIII вв. н.э.)» (руководитель В.Е. Родинкова). Исследуемая территория расположена в зоне формирования восточнославянской национальности, с одной стороны, и высокой изменчивости природных условий - с другой. В настоящее время подавляющее большинство ландшафтов здесь антропогенные, но время их формирования неопределенно. Детальное изучение почвенного покрова позволяет определить возможный доминирующий процесс почвообразования, выявить интенсивность и динамику взаимодействия природных и антропогенных факторов, а также установить возможные причины привлекательности региона для славянского освоения. Проект имеет высокую социальную значимость, так как позволяет актуализировать роль краеведческих знаний в воспитании любви, формировании гражданских понятий и этнической самоидентификации и соответственно формирования у студентов интереса к исследовательской деятельности. 


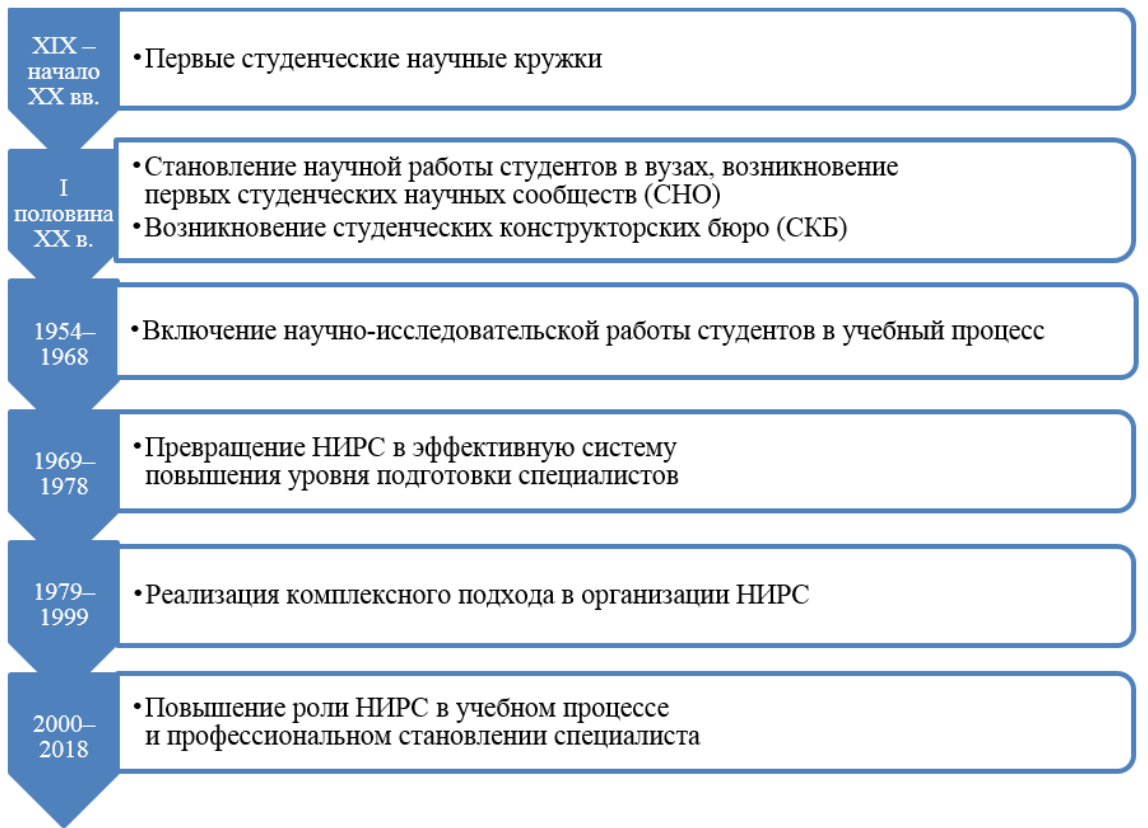

\section{Рисунок 1 - Этапы реализации научно-исследовательской работы студентов в России}

Полевые исследования особенно перспективны для организации научно-исследовательской деятельности. Они могут быть реализованы в период учебных практик. Например, практика по региональной экологии для студентов 3 курса, направления подготовки 05.03.06 - Экология и природопользование была реализована в Медвенском районе Курской области на Курском биосферном стационаре ИГ РАН. Исследуемая территория является примером сочетания разного типа ландшафтов, на территории исследования присутствуют участок типичной степи, лесной биогеоценоз, а также агроландшафт. Изучение взаимовлияния разных типов ландшафтов для будущих специалистов экологов представляет практический интерес, так как позволяет прогнозировать динамику естественных компонентов ландшафтов при наличии антропогенного воздействия или изменении его интенсивности. Практическая направленность деятельности является также фактором аугментации заинтересованности студентов в научно-исследовательской работе. Одним из примеров подобных работ, имеющих практическую значимость, является участие студентов в проекте реконструкции селитебных зон малых городов. Для реализации проектов по повышению комфортности городской среды студентами 2-го курса магистратуры (направление подготовки 05.04.02 - География, направленность Ландшафтное проектирование) были разработаны несколько перспективных планов ландшафтно-рекреационных зон для территории города Курска и, что особенно важно, разработана концепция и практические основы формирования селитебных зон в новых жилых микрорайонах.

Несомненно, для обучающихся в магистратуре студентов отмечается высокая степень готовности и заинтересованности заниматься научно-исследовательской работой. Это обусловлено тем, что одной из главных особенностей обучения в магистратуре является доминирование научно-исследовательского вида деятельности, что в первую очередь характерно для академической магистратуры. На наш взгляд, формы организации научно-исследовательской работы при обучении в магистратуре могут быть различ- ны, но наиболее широкие возможности предоставляет для данного вида деятельности модуль «Производственные практики». В нашем исследовании акцент сделан на процесс организации производственной практики для студентов, обучающихся по направлению подготовки 05.04.02 - География, направленность/профиль Ландшафтное проектирование. Предусмотрено несколько типов практики в данном модуле: практика по получению профессиональных умений и навыков, преддипломная практика и научно-исследовательская работа. Очевидно, научноисследовательская работа, как наиболее продолжительный во временном аспекте и с целевой направленностью тип производственной практики, предоставляет максимальные возможности для вовлечения студентов в исследовательскую деятельность. Технологическая цепочка освоения программы практики выстраивается в логике разработки и реализации научно-практических проектов, обеспечивающих формирование общепрофессиональных, общекультурных и профессиональных компетенций и совершенствование в области профессиональной деятельности $[12 ; 13]$.

Положительным аспектом является региональный аспект исследований и их обусловленность потребностями развития инфраструктуры регионального социума. Формами отчетности по практике являются: индивидуальный план-отчет по практике, индивидуальное научно-исследовательское задание, научная статья, презентация для представления на итоговой конференции по итогам практики.

В ходе производственной практики осуществляется реализация теоретических знаний и практических умений и навыков, полученных за время обучения на основных профилирующих предметах, и совершенствование профессиональных навыков и умений в соответствии с будущим профилем: изучается нормативно-правовая документация, происходит отработка и закрепление методик и методов ландшафтных исследований в рамках организации, являющейся базой практики. На рис. 2 приводится примерное содержание этапов практики по получению профессиональных умений и навыков. 


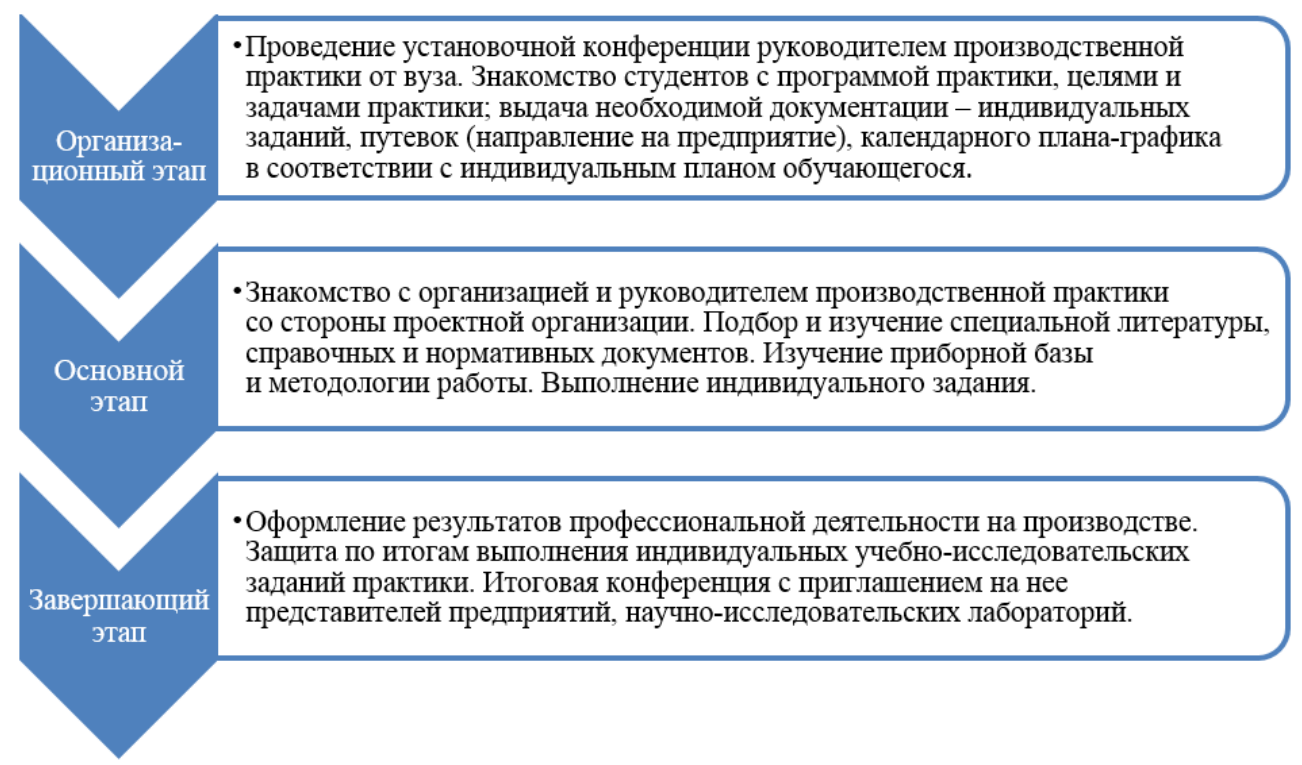

Рисунок 2 - Характеристика содержания этапов содержания производственной практики

Важнейшим видом практик для организации и реализации исследовательской деятельности студентов является научно-исследовательская работа, peaлизуемая в трех семестрах обучения. Предусмотрен в качестве промежуточного контроля зачет за выполнение научно-исследовательской работы. Достоинством научно-исследовательской работы в магистратуре является системная организации, четкие критерии оценивания, поэтапность вовлечения [14-17]. Перед началом прохождения практики обучающийся получает задание на период ее реализации (для научно-исследовательской - это семестр), важно отметить, что задания коррелируют с темой выпускной квалификационной работы обучающегося) (табл. 1).

При оценке качества научно-исследовательской работы, а соответственно - компетентности субъекта деятельности используются объективные, формализованные и фиксируемые показатели [17-20]. Система контроля уровня сформированности компетенций предполагает задания в соответствии с этапом формирования компетенции в период реализации практики. Анализ выполнения программы практики и индивидуальных заданий студентами позволяет сделать вывод о высоком уровне качества отчетов. Кроме того, отмечается активизация представления результатов своих научных исследований научному сообществу: доля студентов, опубликовавших научные статьи и доклады, составляет 95\%. Систематический мониторинг отношения студентов к организации научно-исследовательской деятельности и на основе этого коррекция форм ее организации способствуют повышению заинтересованности студентов и самоорганизации. Оценка сформированности компетенций может проводиться по различным показателям, но, на наш взгляд, основополагающее значение имеют следующие показатели: практический характер научно-инновационной деятельности (участие в фундаментальных ландшафтно-географических исследованиях, модернизации и созданию ландшафтных программ, имеющих общенаучное и прикладное значение), оригинальность идеи и креативный подход, использование новейших технологий ландшафтного планирования и проектирования.
Таблица 1 - Характеристика деятельности обучающегося в рамках научно-исследовательской практики

\begin{tabular}{|c|c|}
\hline $\begin{array}{l}\text { Тема индивиду- } \\
\text { ального научно- } \\
\text { исследователь- } \\
\text { ского задания }\end{array}$ & $\begin{array}{c}\text { Примерный план } \\
\text { деятельности обучающегося }\end{array}$ \\
\hline \multirow{4}{*}{$\begin{array}{l}\text { 1. Разработка } \\
\text { рамочных } \\
\text { ландшафтных } \\
\text { планов } \\
\text { на примере } \\
\text { бассейна } \\
\text { реки Сейм }\end{array}$} & $\begin{array}{l}\text { 1. Изучить направления } \\
\text { ландшафтного планирования } \\
\text { водоохранных зон }\end{array}$ \\
\hline & $\begin{array}{l}\text { 2. Выявить функционально } \\
\text { планировочные и социокультур- } \\
\text { ные предпосылки } \\
\text { водоохранного зонирования }\end{array}$ \\
\hline & $\begin{array}{l}\text { 3. Выявить основные } \\
\text { типологические признаки } \\
\text { ландшафтов бассейна реки Сейм }\end{array}$ \\
\hline & $\begin{array}{l}\text { 4. Выявить перспективы для реа- } \\
\text { лизации ландшафтной программы }\end{array}$ \\
\hline \multirow{4}{*}{$\begin{array}{l}\text { 2. Перма- } \\
\text { культура как } \\
\text { способ } \\
\text { оптимизации } \\
\text { сельских } \\
\text { селитебных } \\
\text { ландшафтов }\end{array}$} & $\begin{array}{l}\text { 1. Определить принципы исполь- } \\
\text { зования методик в рамках перма- } \\
\text { культурного дизайна для сель- } \\
\text { ских селитебных ландшафтов }\end{array}$ \\
\hline & $\begin{array}{l}\text { 2. Охарактеризовать направления } \\
\text { трансформации компонентов } \\
\text { ландшафтов в результате } \\
\text { селитебного освоения }\end{array}$ \\
\hline & $\begin{array}{l}\text { 3. Выявить перспективы } \\
\text { проектирования сельских } \\
\text { селитебных ландшафтов для } \\
\text { малых городов Курской области }\end{array}$ \\
\hline & $\begin{array}{l}\text { 4. Разработать проект } \\
\text { ландшафтного плана } \\
\text { с элементами пермакультуры }\end{array}$ \\
\hline
\end{tabular}

Таким образом, системность организации научноисследовательской работы, последовательное вовлечение обучающихся, мотивационный компонент, обусловленный практической значимостью, обеспечат эффективность ее реализации. Структура и содержание производственной практики соответствует всем вышеизложенным критериям и, несомненно, раскрывает широкие возможности для вовлечения студентов в научно-исследовательскую деятельность и обеспечивает успешное становление будущих специалистов в их профессиональной области. 


\section{Список литературы:}

1. Ананьев Б.Г. Избранные психологические труды: в 2 т. М.: Педагогика, 1980. 286 с.

2. Зимняя И.А. Компетентностный подход. Каково его место в системе современных подходов к проблемам образования? // Высшее образование сегодня. 2006. № 8. С. 21-26.

3. Обухов А.С. Исследовательская позиция личности // Исследовательская работа школьников. 2006. № 1. С. 61-75.

4. Обухов А.С. Развитие исследовательской деятельности учащихся // Народное образование. 2004. № 2. C. 146-148.

5. Леонтович А.В. Об основных понятиях концепции развития исследовательской и проектной деятельности учащихся // Исследовательская работа школьников. 2003. № 4. С. 12-17.

6. Леонтович А.В. Учебно-исследовательская деятельность школьников как модель педагогической технологии // Народное образование. 1999. № 10. C. $152-158$.

7. Сметанина Т.К. Исследовательская деятельность и экологическое образование учащихся // Актуальные задачи педагогики: мат-лы междунар. науч. конф. (г. Чита, декабрь 2011 г.). Чита: Издательство Молодой ученый, 2011. С. 121-124.

8. Сластенин В.А. О моделировании образовательных технологий // Наука и школа. 2000. № 4. C. $50-56$.

9. Цибизова Т.Ю. Структура организации научноисследовательской работы студентов и школьников в техническом университете // Молодые ученые науке, технологиям и профессиональному образованию для устойчивого развития: проблемы и новые решения: сборник научных докладов и тезисов 2-й междунар. конф. стран СНГ. М.: Академия менеджмента инноваций, 2000. Ч. 1. С. 149-152.

10. Алаторцева И.С. Проблема активизации научно-исследовательской деятельности студенческой молодежи // Современное непрерывное образование и инновационное развитие: сборник трудов участников II всерос. науч.-практ. конф. / под ред. проф.
А.Н. Царькова и проф. И.А. Бугакова. Серпухов: МОУ «ИИФ», 2012. С. 485-489.

11. Ткалич С.К., Фазылзянова Г.И., Балалов В.В. Основы исследовательской деятельности в магистратуре «дизайн мультимедиа» (научный инструментарий и мониторинг достижений студентов). М.: Акад. естествознания, $2015.91 \mathrm{c}$.

12. Позднякова А.Л., Чижакова Г.И. Аксиологический подход к формированию ценностного отношения будущего специалиста к профессиональной деятельности // Вестник КГПУ. 2010. Вып (3). С. 84-94.

13. Анищенко В.А., Барангулова С.М. Роль научно-исследовательской деятельности в процессе формирования профессиональной компетентности бакалавров // Вестник ОГУ. 2013. № 5 (154). С. 14-18.

14. Кирьякова А.В. и др. Аксиология образования. Фундаментальные исследования в педагогике: монография. М.: Дом педагогики, ИПК ГОУ ОГУ, 2008. $578 \mathrm{c}$.

15. Малинова О.Ю., Мелешкина Е.Ю. Методика научно-исследовательской работы: учеб. пособие. М.: МГИМО-Университет, 2014. 124 с.

16. Галиуллина Ф.Ш. Научно-исследовательская деятельность студентов как фактор формирования профессиональной компетентности // Вестник Татарского государственного гуманитарно-педагогического университета. 2011. № 3 (25). С. 235-239.

17. Ризен Ю.С., Зазарова А.А., Минин М.Г. Модель подготовки выпускника вуза и повышение эффективности применения образовательных технологий // Проблемы информатики. 2012. Спец. вып. C. 213-220.

18. Ратнер Ф.Л. Психолого-педагогические условия развития творческих способностей студентов в научной деятельности: отечественный и зарубежный опыт. Казань: Изд-во Казан. ун-та, 1999. 44 с.

19. Красовский Ю. Плюсы и минусы обучающего процесса в магистратурах // Ученый Совет. 2009. № 2. C. 37-43.

20. Краснова Т.И. Инновации в системе оценивания учебной деятельности студентов // Образование для устойчивого развития. Минск: Издательский центр БГУ, 2005. С. 438-440.

\title{
PROBLEMS, ESSENCE AND FORMS OF STUDENTS' RESEARCH ACTIVITY ORGANIZATION IN THE SYSTEM OF HIGHER EDUCATION
}

(C) 2019

\author{
Brazhnik Oksana Yurievna, candidate of pedagogical sciences, \\ associate professor of Pedagogy and Professional Education Department \\ Batrachenko Ekaterina Aleksandrovna, candidate of agricultural sciences, \\ associate professor of Geography Department \\ Kursk State University (Kursk, Russian Federation)
}

\footnotetext{
Abstract. This paper describes features of students' research activities organization. The authors consider possibilities of research use while studying the courses of the variable part of the educational program. This paper focuses on the role of industrial practice in the implementation of research activities. The approximate content of practices programs, as well as the typology of tasks aimed at research work intensification is given. The authors emphasize the role of research activities for general professional and professional competencies development. The paper also considers peculiarities of estimation and ways of scientific-research work optimization while studying for the Master's degree. The conducted studies have shown that the assessment of competencies development can be carried out on various indicators, the following indicators are of fundamental importance: practical nature of scientific and innovative activity (participation in fundamental landscape and geographical research, modernization and creation of landscape programs of general scientific and applied importance), originality of the idea and creative approach, use of the latest technologies of landscape planning and design.

Keywords: higher education; research work; research competence; industrial practice; professional skills; general professional competence; professional competence; stage of competence development.
} 